\title{
Participación activa del alumno en prácticas de microscopía
}

\author{
Josefa Larrán-López, José Aparicio-Patino, Antonio López-Muñoz
}

\begin{abstract}
Resumen. La implantación del Espacio Europeo de Educación Superior promueve un cambio en la metodología docente centrando su interés en el proceso de aprendizaje del estudiante y en la adquisición de una serie de competencias específicas y transversales. Con objeto de adecuar el proceso de enseñanza-aprendizaje hacia las actuales directrices introducimos una nueva actividad en nuestra práctica docente. Se pretende fomentar la participación activa de los alumnos y proporcionar un escenario adecuado para el desarrollo de distintas competencias transversales que nos permitan ponerlas de manifiesto y, por tanto, evaluarlas. La actividad consiste en la exposición oral, por parte de los alumnos de la asignatura 'Biología celular y tisular humana' de primer curso del grado de Fisioterapia, de una revisión/resumen del tema a tratar en las clases prácticas, así como de la explicación de las características microscópicas de las muestras a observar en dicha práctica. Tras la exposición se realiza una evaluación por parte del resto de compañeros y al finalizar el curso los alumnos ofrecen su valoración de la experiencia. Con esta actividad se logra una mayor participación de los alumnos y se mejora la adquisición y desarrollo de competencias específicas y transversales. El profesor tiene la oportunidad de asumir el papel de guía y gestor del aprendizaje del alumno. Los alumnos valoran positivamente la experiencia.
\end{abstract}

Palabras clave. Competencias transversales. EEES. Espacio Europeo de Educación Superior. Participación activa del alumno. Prácticas de microscopía.

\section{Student's active participation in microscopy laboratory}

Summary. The implantation of the European Higher Education Area promotes a change in teaching methodology focusing its interest in the process of student learning and the acquisition of a series of specific and generic competences. In order to adapt the teaching-learning process to the current guidelines we introduce a new activity in our teaching practice. It aims to encourage active student participation and provide a stage for the development of various generic competences that allow us to highlight and thus evaluate them. The activity is the oral presentation of a review of the issue of practicing class as well as the explanation of the microscopic characteristics of the samples to be observed in the practice, by students of the subject 'Human Cell and Tissue Biology' in the first-year degree in Physiotherapy. After exposure evaluation are performed by peers and in the end of the course we test students about the experience. With this activity there is a greater student participation and improves the acquisition and development of specific and transversal competences. The teacher has the opportunity to assume the role of guide and facilitates student learning. Students value the experience positively.

Key words. EHEA. European Higher Education Area. Generic competences. Microscopic practice. Student participation.

\section{Introducción}

La actual organización de las enseñanzas universitarias con la implantación del Espacio Europeo de Educación Superior promueve un cambio en la metodología docente al centrar su interés en el proceso de aprendizaje del estudiante. Inmersos en una sociedad donde el incremento de la producción científica es vertiginoso y su acceso se facilita con la implantación y uso de las tecnologías de la información y la comunicación, el objetivo principal es la formación de individuos que alcancen un alto nivel de conocimiento pero que también sean capaces de analizar e integrar la información que les llega, de mejorar sus habilidades de resolución de problemas y comunicación, y de reflexionar sobre su propio papel en el proceso de aprendizaje, dando lugar a los profesionales que reclama la sociedad actual, capaces de adquirir conocimiento de forma independiente a lo largo de toda la vida y emplearlo para resolver problemas imprevistos [1]. Se demanda al alumno un mayor compromiso y responsabilidad por su propio aprendizaje y al profesor que sea el iniciador, guía y facilitador de ese aprendizaje [2]. Esto lleva al profesorado universitario a replantear su trabajo docente e implica una revisión de las me-
Facultad de Enfermería y Fisioterapia. Cádiz, España.

Correspondencia:

Profa. Josefa Larrán López. Facultad de Enfermería y Fisioterapia. Avda. Ana de Viya, 52. E-11009 Cádiz.

E-mail:

josefa.larran@uca.es

Conflicto de intereses: No declarado.

Competing interests: None declared.

(c) 2013 FEM 
todologías empleadas en su práctica diaria y por tanto a un cambio de rol, dejando de ser un mero transmisor de información para ejercer un papel de guía, acompañante y orientador [3,4].

En este contexto, los alumnos deben lograr la adquisición y desarrollo de competencias que lo capaciten para su posterior integración en el mundo laboral, por lo que se deben introducir metodologías que faciliten, potencien y desarrollen la adquisición de distintas competencias transversales por parte de los estudiantes y permitan ponerlas de manifiesto y, por tanto, evaluarlas por parte del profesor.

La histología humana es una ciencia morfológica básica en los estudios de ciencias de la salud y proporciona la descripción de la estructura microscópica del organismo humano aportando datos útiles necesarios para comprender el ser humano en su normalidad y en los distintos cuadros lesionales que lo afectan, así como los mecanismos que conducen a la defensa y reparación [5]. Para la comprensión de la histología, que requiere el desarrollo de imágenes mentales en tres dimensiones, son muy importantes las clases prácticas y la visualización de imágenes y esquemas que favorezcan la correlación de lo estudiado con imágenes microscópicas. En años anteriores hemos desarrollado distintas actividades para poner a disposición del alumno cada vez más material iconográfico a través de medios electrónicos, con el fin de facilitar su estudio independiente y la posibilidad de completar su trabajo de prácticas. Sin embargo, con esto no logramos con plenitud la participación activa del alumno ni la adquisición y desarrollo de ciertas competencias que tanto se demanda en los nuevos estudios de grado.

En este artículo presentamos nuestra experiencia en el diseño e introducción de una actividad que implica el trabajo en grupo y la exposición oral por parte de los alumnos en las clases prácticas. Los objetivos que nos planteamos son fomentar la participación activa de los alumnos en el proceso de enseñanza-aprendizaje y proporcionar la posibilidad de que desarrollen distintas competencias que no están al alcance del estudiante con la utilización del clásico método expositivo por parte del profesor. Igualmente se pretende la asunción de los nuevos roles que el profesorado debe asumir. Para lograr, si cabe, una mayor participación y colaboración de los estudiantes utilizamos la evaluación por iguales', ya que los alumnos valoran la exposición de sus compañeros, y para conocer su opinión sobre la actividad realizan también una valoración individual voluntaria sobre esta experiencia, recogiéndose comentarios y sugerencias para su mejora.

\section{Materiales y métodos}

Esta actividad se ha llevado a cabo en la asignatura de carácter obligatorio 'Biología Celular y Tisular $\mathrm{Hu}$ mana', que engloba los contenidos de histología humana y está incluida en el primer curso de los estudios del Grado en Fisioterapia de la Universidad de Cádiz. La experiencia se inicia en el curso 20092010, con la puesta en marcha de los estudios del Grado en Fisioterapia en la Universidad de Cádiz. Hasta la actualidad, curso 2011-2012, han participado un total de 184 alumnos. Al inicio de cada curso académico se informa a los alumnos de la actividad y de sus objetivos. Cuando se completa la matriculación y disponemos de los listados de grupos de prácticas, se organizan los subgrupos de trabajo dentro de cada uno de ellos. El número de alumnos que consideramos más idóneo para formar estos grupos es de dos o tres, ya que así se asegura que todos los componentes del grupo participan en la exposición oral. A cada grupo se le asigna una fecha para la exposición oral y el tema en cuestión correspondiente a una determinada sesión práctica y ya visto con anterioridad en las clases teóricas. En la primera reunión con cada grupo de exposición, el profesor suministra un guión con aspectos que deben estar presentes en la presentación del tema, así como imágenes tomadas de las preparaciones histológicas a manejar en esa sesión práctica, seguido de una explicación de dichas preparaciones. Además de la reunión inicial, se realiza al menos una más, previa a la exposición, para lograr orientar el trabajo del alumno y la corrección de cualquier error que se detecte.

Los alumnos deben recabar la información necesaria para realizar una presentación utilizando formato electrónico tipo power-point o similar. La duración de la exposición es de un máximo de 15 minutos. El resto de la clase práctica se dedica a la observación microscópica individual de las muestras histológicas correspondientes y a la elaboración del cuaderno de prácticas. Las imágenes utilizadas en la exposición se suben siempre al campus virtual (plataforma Moodle), ya que formarán parte de la base de imágenes que se utilizará para la evaluación de la parte práctica de la asignatura. Ello facilita el trabajo del estudiante porque le permite completar el cuaderno de prácticas fuera del horario presencial.

Después de cada exposición, el resto de alumnos de ese grupo de práctica, de forma anónima, evalúan a sus compañeros indicando qué le parecen los recursos utilizados, la calidad del contenido, el orden de la exposición y la claridad de la exposición, y 
otorgan una calificación global, pudiendo realizar también comentarios y sugerencias. Las medias de calificaciones que ha obtenido cada grupo, según la evaluación entre iguales, se da a conocer en el campus virtual.

Para saber la opinión de los alumnos sobre la actividad se pone a su disposición, a través del campus virtual, un cuestionario de tipo voluntario al finalizar el curso (Tabla I).

\section{Resultados}

La experiencia se llevó a cabo durante los últimos tres cursos académicos con total normalidad y como una actividad más incluida en la programación. Los alumnos han participado mayoritariamente con interés y se han realizado una media de dos reuniones entre el profesor y el grupo de exposición. Dentro y fuera de estas reuniones se resolvieron dudas de forma presencial o a través de tutoría electrónica.

En la tabla II se ofrece la media de los resultados de la evaluación por los compañeros del grupo de prácticas; se observan valores muy similares en todos ellos y cercanos a la puntuación máxima. En esta evaluación entre iguales los alumnos han realizado distintos comentarios que se incluyen también cuando se da a conocer la puntuación en el campus virtual. Destacamos algunos comentarios positivos, como 'la forma de exponer el tema me ha gustado, lo han defendido bien', 'se han explicado muy bien,' 'ha sido una de las exposiciones más claras'... Otros comentarios son de justificación y comprensión hacia los compañeros: 'hay que ponerse en la situación de la persona que está explicando, muchas veces los nervios te pueden', 'han tenido problemas con la presentación power-point, pero aun así han sabido improvisar y defender el tema perfectamente'. Otros comentarios son más críticos: 'se notaba que no estaba muy bien preparado', 'se han equivocado en algunas cosas'.

El cuestionario voluntario sobre la percepción de la actividad lo realizan un total de 127 alumnos. Tras analizar las respuestas podemos indicar que a los alumnos, en general, les parece una buena forma de ponerse en contacto con los compañeros, sobre todo con aquellos que no conocían, y así un $97,7 \%$ responde que les ha ido muy bien en el trabajo con los compañeros y que ha habido buena coordinación. Mayoritariamente $(80,2 \%)$ los alumnos indican que el trabajo lo han realizado de forma conjunta y un $85 \%$ piensan que todos los componentes del grupo han trabajado por igual y se merecen la misma calificación. Un 15\% difieren de esto último
Tabla I. Cuestionario facilitado a los alumnos.

¿Qué le ha parecido el trabajo con los compañeros?, ¿ha habido una buena coordinación?

¿El trabajo se ha realizado conjuntamente o se ha repartido y cada uno ha hecho su parte individualmente?

¿Cree que se ha trabajado por igual?, ¿cree que todos se merecen la misma calificación?

¿Ha aprendido algo?, ¿le ha gustado la experiencia?

Si lo desea, puede realizar alguna observación o comentario sobre la actividad

En su opinión, ¿este tipo de actividad facilita la comunicación alumno-profesor?

En su opinión, ¿este tipo de actividad facilita el aprendizaje de la asignatura?

En su opinión, ¿este tipo de actividad facilita la participación activa por parte del alumno?

En su opinión, ¿este tipo de actividad aumenta la motivación hacía la asignatura?

En su opinión, ¿la exposición por parte de otros compañeros le parece positiva?, ¿le ayuda a revisar la materia o darse cuenta de los fallos y aciertos en la exposición de otros?

En su opinión, ¿encuentra beneficio en la realización de esta actividad?, ¿le parece positiva?

y algunos emiten comentarios como: 'pienso que no todo el mundo se ha esforzado de la misma manera; mientras que unos hemos intentado prepararnos de la mejor manera posible nuestra parte de la exposición, otros se han dedicado a leerla simplemente'. También realizan comentarios sobre la puntuación: 'creo que hay mucho compañerismo, hemos sido bastantes generosos,' 'a veces se ha puntuado más por la afinidad con el grupo expositor que por la exposición en sí.

El 100\% de los alumnos indican que han aprendido algo y que les ha gustado la experiencia. Piensan que es una experiencia positiva y lo apoyan con comentarios como: 'sinceramente creo que esta actividad deberían utilizarla los demás profesores porque ayuda mucho en cuanto revisión, comprensión y resolver dudas de los temas, así como a tener un archivo más sobre cada tema a modo de resumen para facilitar el estudio de ellos; en ultima instancia nos ayuda a salir y hablar en público, algo muy difícil para los alumnos,' 'he aprendido mucho, tanto a la hora de hablar en público como en el tema que expusimos', 'siempre que se realiza un trabajo se aprende, y más al buscar la información y trabajarla para ponerla lo mejor posible en el powerpoint y buscar un vocabulario para que se entienda lo que se va a explicar'.

El 89,7\% de los alumnos que realizan el cuestionario opinan que este tipo de actividad facilita la comunicación alumno-profesor. El 98,5\% indican 
Tabla II. Media de los resultados de la evaluación por los compañeros del grupo de prácticas.

\begin{tabular}{lccccc}
\hline & $\begin{array}{c}\text { Calidad del contenido } \\
\text { (sobre 2) }\end{array}$ & $\begin{array}{c}\text { Recursos utilizados } \\
\text { (sobre 2) }\end{array}$ & $\begin{array}{c}\text { Orden de la exposición } \\
\text { (sobre 2) }\end{array}$ & $\begin{array}{c}\text { Claridad de la exposición } \\
\text { (sobre 2) }\end{array}$ & $\begin{array}{c}\text { Calificación global } \\
\text { (sobre 10) }\end{array}$ \\
\hline Curso 2009-2010 & 1,8 & 1,7 & 1,8 & 1,6 & 8.5 \\
\hline Curso 2010-2011 & 1,8 & 1,7 & 1,8 & 1,6 & 8,1 \\
\hline Curso 2011-2012 & 1,8 & 1,7 & 1,8 & 1,5 & 8,2 \\
\hline
\end{tabular}

que esta actividad facilita el aprendizaje de la asignatura y la participación activa, y el $80,3 \%$, que aumenta la motivación hacia la asignatura. Al 100\% de los alumnos les parece positiva la exposición por parte de los compañeros y consideran que les ayuda a revisar la materia o darse cuenta de los fallos o aciertos en la exposición de otros: 'las exposiciones de los demás nos ayudan a ser críticos puesto que vemos si lo hacen bien, mal..., y con eso podemos aprender a hacer una exposición.

En resumen, el 98,5\% de los alumnos que cumplimentan el cuestionario encuentran beneficio en la realización de esta actividad y les parece positiva.

\section{Discusión}

El Espacio Europeo de Educación Superior obliga a la organización de los estudios universitarios teniendo como figura clave y central al alumno y la adquisición por su parte de una serie de competencias, entendidas como el conjunto de conocimientos, habilidades, destrezas, actitudes y valores, y que se construyen a partir de una serie de actividades de aprendizaje [6]. Uno de los requisitos fundamentales para lograr que los alumnos adquieran distintas competencias es la utilización de la metodología adecuada por parte del profesor [7]. Al objeto de enfocar la metodología del proceso de enseñanza-aprendizaje de nuestra práctica docente a estos requerimientos ponemos en marcha esta actividad. La asignatura de 'Biología Celular y Tisular Humana' del Grado en Fisioterapia de la Universidad de Cádiz tiene como uno de sus objetivos principales el estudio microscópico de las diferentes células, tejidos, órganos, aparatos y sistemas que componen nuestro organismo. La observación e interpretación de imágenes microscópicas son habilidades que deben aprenderse y perfeccionarse en las clases prácticas, indispensables en la organización de la docencia de esta materia. Tradicionalmente es el profesor quien se encarga de realizar la introducción y explicación en cada clase práctica, pero buscando una mayor participación de los alumnos y para proporcionar entornos educativos que mejoren la adquisición de competencias tanto específicas como transversales, organizamos e introducimos esta actividad.

Creemos que con esta actividad se consigue promover la adquisición de distintas competencias transversales, incluidas en la memoria del Grado en Fisioterapia, como trabajo en equipo, razonamiento crítico, capacidad de organización y planificación, capacidad de gestión de la información, creatividad, análisis y síntesis. Pensamos que son esenciales para los estudiantes de ciencias de la salud, no sólo útiles en el tiempo que van a pasar en la universidad, sino también para su futura actividad profesional en una sociedad donde los conocimientos científicos van en aumento día a día. Igualmente se facilita la consecución de competencias específicas de la materia, ya que les obliga a revisar los conocimientos adquiridos en las actividades teóricas -que sólo suelen realizar en la preparación previa de los exámenes- y a fijar su atención en las imágenes, en su identificación y descripción. El material utilizado, las imágenes microscópicas, se incorporan al campus virtual para formar parte de la base de imágenes que se utilizará en la evaluación práctica de la asignatura, facilitando así el estudio.

Esta actividad se incluyó dentro del programa de innovación educativa universitaria para el personal docente e investigador impulsado por la Universidad de Cádiz. Según Zabalza [8], 'innovar no es sólo hacer cosas distintas, sino hacer cosa mejores. La innovación es introducir cambios justificados. [...] Una condición de la innovación es la practicidad, deben ser viables (posibilidad de ser llevada a cabo) y prácticas (que no se quede en meras palabras, sino que dé resultados tangibles). Pensamos que esta actividad cumple tales premisas, ya que introducimos en nuestra actividad docente diaria cambios con intención de hacer las cosas mejores, justificados en el interés de fomentar la participación 
activa del alumno y propiciar su aprendizaje autónomo, y en la necesidad de potenciar la adquisición de competencias transversales que de otra forma no podemos poner de manifiesto. La actividad es igualmente viable y práctica porque podemos ponerla en marcha dentro de la estructura del marco horario de la programación de la asignatura y con los recursos disponibles en el centro, y da resultados tangibles porque los alumnos participan con interés y se logran los objetivos planteados.

Consideramos positiva la experiencia llevada a cabo estos años, pero reconocemos también que supone un mayor esfuerzo y tiempo en la organización y desarrollo de la docencia por parte del profesor, si bien se ve recompensado en los resultados y la buena acogida que tiene por los alumnos.

En conclusión, consideramos útil esta actividad porque logramos mayor participación de los alumnos en el proceso de enseñanza-aprendizaje. Se mejora la adquisición de competencias específicas propias de una formación histológica y la adquisición de competencias transversales que de otro modo no tenemos oportunidad de poner de manifiesto. Igualmente, el profesor asume y desarrolla en mayor medida el rol de guía, orientador y facilitador del aprendizaje. La implicación de los alumnos en el proceso de aprendizaje es sumamente beneficiosa, se logra una mayor interactividad entre ellos y también con el profesor, y se traduce en una experiencia positiva, siendo muy bien valorada por ellos como exponen en los cuestionarios de valoración.

\section{Bibliografía}

1. Dochy F, Segers M, Sluijsmans D. The use of self-, peer and co-assessment in higher educations: a review. Studies in Higher Education 1999; 24: 331-50.

2. Morales-Vallejo P. Nuevos roles de profesores y alumnos, nuevas formas de enseñar y aprender. In Prieto-Navarro $L$, coord. La enseñanza universitaria centrada en el aprendizaje. Estrategias útiles para el profesorado. Barcelona: Octaedro; 2008. p. 17-27.

3. Bozu Z, Canto-Herrera PJ. El profesorado universitario en la sociedad del conocimiento: competencias profesionales docentes. Revista de Formación e Innovación Educativa Universitaria 2009; 2: 87-97.

4. Cerrillo-Martín MR, Izuzquiza-Gasset D. Perfil del profesorado universitario. Revista Interuniversitaria de Formación de Profesorado 2005; 20: 1-5. URL: http://www.aufop.com/ aufop/revistas/arta/digital/123/1115. [17.05.2012].

5. Campos-Muñoz A. Objetivos conceptuales y metodológicos en la investigación histológica. Educ Med 2004; 7 (Supl 1): 36-40.

6. Cano-García ME. La evaluación por competencias en la educación superior. Profesorado. Revista de Currículo y Profesorado 2008; 12: 1-16. URL: http://www.ugr.es/ recfpro/ rev123COL1.pdf. [18.04.2012].

7. García-Ruiz MR. Las competencias de los alumnos universitarios. Revista Interuniversitaria de Formación de Profesorado 2006; 20: 253-69. URL: http://www.aufop.com/ aufop/uploaded_files/articulos/1211507434.pdf. [17.05.2012].

8. Zabalza MA. Innovación en la enseñanza universitaria. Contextos Educativos 2003-2004; 6-7: 113-36. URL: http:// dialnet.unirioja.es/servlet/articulo?codigo=1049473. [19.04.2012]. 